Başvuru Tarihi: 13.07.2017 Received Date: 13.07.2017

Yayına Kabul Tarihi: 09.10.2017 Accepted Date: 09.10.2017

Yayınlanma Tarihi: 29.01.2018 Published Date: 29.01.2018
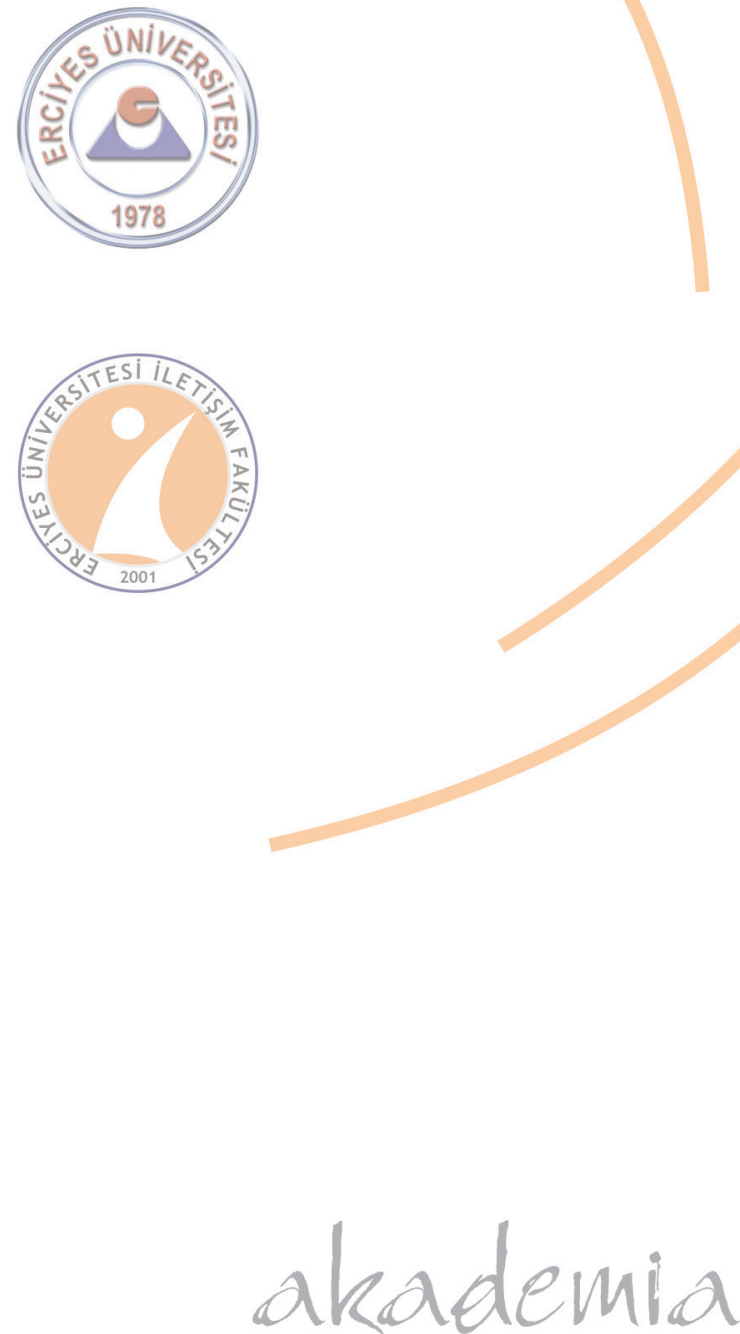
ISSN:1308-3198

Erciyes İletişim Dergisi akademia 2018

Cilt (Volume): 5, Sayı (Number): 3, (28-38)
Sibel ONURSOY (Doç. Dr.)

Anadolu Üniversitesi İletişim Bilimleri Fakültesi

sonursoy@anadolu.edu.tr

\title{
GÖZ TAKİBİ DENEYIMIYYL GAZETEDE RENK FAKTÖRÜ
}

\section{Öz}

Gazetelerde renk kullanımının izleyicinin haberi kolay ve çabuk anlaması için faydalı olduğu, rengin varlığının bilişsel süreci hızlandırdığı; ayırt etmeyi sağladığı ve rengin çağrışım özelliği algı sürecini zenginleştirdiği düşünülmektedir. Bu çalışmada gazete okurlarının renklere verdikleri duygusal ve davranışsal tepkiler değerlendirilmektedir. Bu deneysel çalışma haber fotoğraflarında rengin siyah-beyaz karşısındaki duygusal ve davranışsal etkisini keşfetmek için tasarlanmaktadır. Okurların renk karşısında verdiği tepkiler habere ayırdıkları süre, ilgi, akılda kalıcılık üzerinde etkili olabilir. Bu araştırma gazete ya da haber tasarımında rengin karakteristik önemi ve etkisi üzerine odaklanan ampirik bir çalışmadır. Bu deneysel araştırmada medyada yaygın olarak kullanılan boyutlarda hazırlanan renkli ve siyah beyaz maket sayfalar katılımcılara okumaları için gösterilmektedir. Araştırmaya haftada en az dört gün gazete okuyan 320'nin üzerinde üniversite öğrencisi katılmaktadır. 'ASL Mobile Eye' göz izleme cihazı ile elde edilen veriler 'EyeVision' yazılımı ile değerlendirilerek nokta koordinatlarına dönüştürülmektedir. Yedi nokta üzerinden kalibrasyon sağlanmaktadır. Verilerin değerlendirilmesinde mekânsal nokta örüntüleri dikkate alınmaktadır. Bu araştırma sonucuna göre, okurlar renkli sayfalarda haber okumak istediklerini belirtmekte ancak renk faktörünün okunurluğu artırmada pozitif bir rolü görülmemektedir.

Anahtar sözcükler: Göz Takibi, Renk Faktörü, Okunabilirlik, Gazete Tasarımı.

\section{READER'S EYE TRAKING EXPERIMENT TOWARD COLOR ELEMENT OF NEWSPAPER}

\begin{abstract}
The use of color in newspapers is useful for easy and quick understanding of the viewer, the fact that the coloring process accelerates the cognitive process; And that the color associative feature enriches the process of perception. The emotional and behavioral responses of the readers to the colors are evaluated in this study. This empirical study is designed to explore the emotional and behavioral effects of color against black-white on news photographs. The reactions that readers give to colors can affect the amount of they spend time on news, interest and in mind. This research is an empirical study focusing on the characteristics and effect of color in newspaper or news design. In this study, colored and black and white model pages prepared in media commonly used sizes are shown for participant readings. More than 320 university students are participating in the research, who are at least four days a week reading a newspaper. The data obtained with the ASL Mobile Eye tracking device is converted to the point coordinates using EyeVision software. Calibration over seven points is provided. Spatial point patterns are taken into consideration in the evaluation of the data. According to this research result, although the readers want to read news on colored pages, it cannot be said that the color factor has increased readability.
\end{abstract}

Keywords: Eye Tracking, Color Factor, Readibility, Newspaper Design. 


\section{Giriş}

Renk görünür dalga boylarının tümünün varlığı olarak tanımlanır ve şekil, boyut, parlaklık, çizgi, açı ve kontur ile bağlantılı olarak, gerçek dünyanın bazı fiziksel yönlerini tanımlayan algisal bir özelliktir (Gilbert ve Schleuder, 1990, 749). Gazete, dergi ve haber sitelerinde her gün çok miktarda renkli fotoğrafın haberlere eşlik ettiği görülmektedir. Çoğu editör fotoğrafik mesajların daha iyi anlaşılması kaygısıyla çok sayıda ve renkli fotoğraf kullanımına yönelmekte, basın fotoğrafçıları da izleyicinin mesajı idrak etmesinde karışıklığa meydan vermeyecek basit ve net kadrajların peşinden gitmektedir (Gilbert, 1986, 749).

Gazete tasarımında rengin önemli ve etkili olduğu düşünülmesine rağmen, tasarımdaki karakteristik etkisi üzerine pek az araştırma gerçekleştirilmektedir (Garcia \& Stark, 1991). Teknolojik yenilikler ve maliyetlerin düşmesi yayıncılık dünyasında renk kullanımını artırmaktadır. Gazetelerde rengin kullanımından kaçınılması karmaşık görünüm ya da modası geçmiş görünme korkusundan kaynaklanıyor gibi görünmektedir. Estetik amaçlı olarak renk kullanımı için bazı kurallar mevcut olsa da gazetelerde rengin etkisine konusunda çok az ampirik çalışma mevcuttur (Detenber ve Winch, 2001).

Haber fotoğraflarında rengin varlığı, yokluğu ya da karmaşıklığı yönlendirici rol üstlenebilmektedir. İnsanların fotoğrafı anlamadaki zihinsel çabası fotoğraftaki harcadıkları süre ve bireysel hafızalarıyla ilişkilidir. İnsan dışında sadece birkaç hayvan türü renk hissini yaşamaktadır. Son renk araştırmalarına göre renk, uzaydaki yerleşim, şekil, boyut ve diğer algısal özelliklerle birlikte imajla bütünleşmektedir (Treisman, 1977; Treisman \& Gelade, 1980; Treisman, Stykes \& Gelade, 1977).

Güncel deneyimler, rengin görsel bir alanda ilgili uyaranları bulmak için oldukça etkili ipuçlarına sahip olduğunu göstermektedir. Görsel araștırmalarda, dikkatin direkt olarak seçimi yönlendirdiği doğrulanmakta, sonrasında da renk, dikkati dağıtan öğeler içinden hızlı ve doğru tanımlamayı sağlamaktadır (Örn., Brawn \& Snowden, 1999; Moore \& Egeth, 1998). Ancak rengin dikkati yönlendirmesiyle ilgili olarak tartışmalar mevcuttur. Bir taraftan renk ipuçlarının konuma hızla odaklamayı sağladığı için, dikkat ve odaklanmada etkili olduğu, diğer taraftan rengin dikkati çekmede önceliği olmasa bile konuma dikkati toplamada araci rol üstlenmesi gibi (Moore \& Egeth, 1998; Shih \& Sperling, 1996). Diğer taraftan uyarının aracı olmadan da konumsal olarak algılanabileceği sonuçları elde edilmiștir (Vierck and Miller, 2005, 2008). Andersen ve arkadaşlarının araștırmalarına göre, dikkatin mekânsal odaklanmasında aracılık olmadan da uyaranların renklerinden dolayı seçilebildiği belirtilmektedir (Andersen vd., 2009).

Bazı araştırmalar renklerin anlamları ve renk tercihleri kültürler arasında tutarlılık olmadığını göstermektedir. Genel olarak sıcak renkler (örneğin kırmızı) soğuk renklerden (örneğin mavi) daha fazla uyarılma ve dikkat çekmektedir (Birren, 1978), soğuk renkler sıcak renklerden daha çok rahatlık ve zevk vermektedir (Jacobs and Seuss, 1975). Ayrıca psikoloji literatüründe kırmızı arka planın mavi arka plandan daha fazla dikkat çektiğinin bulunduğu çalışmalar mevcuttur (Bellizzi, Crowley and Hasty, 1983). Schindler (1986), reklamların izleyici kitlesinin dikkatini çekmek için, genelde firmaların yüksek kontrastlı reklamlar kullandığını belirtmektedir (Moore, Stammorjohan ve Coulter, 2005, 73). Ayrıca, rengin varlığı ve şekil, doku, boyut ve yerleşim gibi diğer görsel özellikler görselin bilgi miktarını artırabilmektedir (Bousfield, Esterson vd., 1957, Wicker, 1970).

Renkli ve siyah-beyaz fotoğraf konusunda Franken'in araştırmalarında (1977) renkli fotoğrafların ilk bakışta izleyiciler tarafından kolayca tanındığı, siyah beyaz fotoğrafların daha zor idrak edildiği görülmektedir. Renk, nesnenin tanınmasında, daha çok bilgi verir ve diğer algısal özelliklerden daha güven vericidir (Deregowski, 1976; Arıkan, 2008, 13). Dolayısıyla görsel süreçte hızlandırıcı bir rol üstlenebilir ve daha az zihinsel çaba gerektirebilir. Zihinsel çaba düşünme sırasında gereken mental kapasite miktarı olarak tanımlanabilir. Tanıyıcı hafıza ise aşinalık hissi olarak tanımlanabilir (Glass ve Holyoak, 1986). 
Bazı çalışmalar, renkli imajların siyah beyaza nazaran daha az zihinsel çaba gerektirdiği, karmaşık imajların basit imajlardan daha az zihinsel çaba gerektirdiği varsayımlarına dayanmaktadır (Gilbert ve Schleuder, 1990, 750). Deneysel bulgular, renk veya karmaş1k elemanlara sahip görüntülere maruz bırakılmanın, siyah beyaz görüntülere nazaran farklı duyusal yanıtlarına yol açtığını desteklemektedir. Renk hatırlamayı kolaylaştırmamakta dahası renkli görsel karmaşa daha fazla zihinsel çaba gerektirmektedir. Renk, zihinsel anlamda imaj işlemeyi hızlandırmakta, karmaşıklığı azaltmakta ve imajın hafızada kalıcılığını artırmaktadır. $\mathrm{Bu}$ nedenle gazetelerde renk kullanımının izleyicinin fotoğrafı kolay ve çabuk anlaması için faydalı olduğu düşünülmektedir. Rengin varlığ iki şekilde bilişsel süreci hızlandırır; ayırt etmeyi sağlar ve rengin çağrışım özelliği algı sürecini zenginleştirir. Renk, hafıza sürecinde zihinsel çaba üzerinde etkilidir. Siyah-beyaz imajların işlenmesi daha uzun sürer çünkü rengin ipuçlarına sahip değildir (Gilbert and Schleuder, 1990).

Renkli görüntülerin dikkat çekici özelliklere sahip oldukları düşünüldüğünden reklamlarda da yaygın olarak kullanılmakta ve parlak renk uygulamaları giderek daha popüler hale gelmektedir.

Poynter araştırmalarında haber sayfaları ve renkle ilgili elde edilen bazı temel sonuçlar şöyle sıralanabilir: Fotoğraflar dikkat çekicidir; renkli fotoğraflar siyah-beyaz olanlardan daha önce görülmektedir. Gözü sayfaya çekmek için renk güçlü bir araçtır. Okurun sayfaya girişini sağlayan baskın eleman genelde fotoğraf ya da illüstrasyonlardır. İçerisinde görseller bulunan haber kutuları, görsel elemanı olmayanlardan daha çok dikkati çekmektedir. Yan yana iki sayfa okur tarafından tek sayfaymış gibi algılanmaktadır. Okurlar sağdaki sayfadan bakmaya başlamakta daha sonra soldaki sayfaya geçmektedir. Okurlar rengi sevmektedirler ve aynı zamanda rengin içindeki yazıları renksiz olandan daha çok okuduklarını söyleseler ise de gerçek böyle değildir. Renk okurlara bir yanılsama yaratmakta sayfada göründüğünden daha çok bilgi varmış hissi vermektedir. İmajlar (fotoğraflar ve grafikler) yazılardan önce görülmektedir. En çok fotoğraflara bakılmakta ardından başlık ve reklamlar gelmekte ve sonrada kısa yazılar ve foto altı yazıları okunmaktadır. Metinler en az okunanlardır. En çok dikkati sayfanın üst kısmı çekmektedir. Baskın başlıklar gözü çekmekte ve sayfaya ilk girişi sağlamaktadır. Fotoğrafsız metinlerde de sayfaya ilk girişi başlıklar sağlamaktadır. Kısa paragraflara uzunlara göre iki kat daha fazla bakılmaktadır. Standart tek sütunlu haber formatı çoklu sütunlardan daha çok tercih edilmektedir (Poynter Eye-Track Araştırma Raporları, 2004).

\section{Araştırmanın Amacı}

Yukarıda açıklanan literatür göz önüne alınarak bu araştırmanın amacı şu şekilde açıklanabilir: Bir deneysel çalışma olan göz izleme deneyimiyle, okurların haber sayfalarında rengin, siyah-beyaz karşısındaki duygusal ve davranışsal etkisini keşfetmek, okurların renk karşısında verdiği tepkiler ve haberlere ilgileri üzerindeki etkisini değerlendirmektir. Bu araştırma gazete ya da haber tasarımında rengin karakteristik önemi ve etkisi üzerine odaklanan ampirik bir çalışmadır.

\section{Araştırmanın Sınırlılıkları}

Veriler Anadolu Üniversitesi öğrencileri ve çalışanların katılımından elde edilmektedir. Göz takibi aşamasında zaman zaman katılımcıların göz bozukluğu gibi fiziksel sorunlar nedeniyle veri kayıpları yaşanmıştır. 500'e yakın katılımcıdan ancak 320 katılımcıdan temiz veri elde edilmektedir. Elde edilen bulgular bu araştırmanın katılımcılarıyla sınırlıdır.

\section{Araştırmanın Yöntemi}

$\mathrm{Bu}$ çalışmada veri toplamak için iki tür teknikten yararlanılmaktadır. Öncelikle katılımcılardan demografik bilgilerini ve gazete okuma alışkanlıklarını araştıran bir anket uygulanmakta ardından göz takibi cihazıyla göz izleme kayıtları alınmaktadır. Çalışmanın hazırlık evresinde literatür bilgileri göz önüne alınarak, iki ayrı renkli maket sayfa ve bu sayfaların iki siyah-beyaz versiyonu oluşturulmuştur. Bu maket sayfaların her birinde 15 farklı konuda haber 
örneği yer almaktadır. Bu 15 haberin 11 tanesi fotoğraflı haberdir ve her biri siyaset, spor, çevre, teknoloji, iş/ekonomi, dış ilişkiler, magazin, sağlık, polis/adliye gibi farklı konuları kapsamaktadır. Haber örnekleri ve fotoğraflar bu çalışma için uygun formattaki haberler içinden seçilmiştir. Maketler gerçek gazete sayfası boyutlarında ( $57 \mathrm{~cm}$ x $82 \mathrm{~cm}$ kâğıt boyutuna uygun) sayfa tasarımı QuarkXpress ve Photoshop grafik yazılımları kullanılarak tasarlanmıştır. Gerçek gazete sayfasını andıracak biçimde ve görüntüde, ulusal gazetelerde uygulanan yaygın iki farklı tasarım biçiminde hazırlanmıştır. Her katılımcının ancak bir maket sayfayı görmesine izin verilmiştir. Bu çalışmada "ASL, Mobile Eye" göz izleme cihazı ve EyeVision yazılımı kullanılmaktadır. ASL Mobile Eye göz izleme cihazı ile elde edilen veriler EyeVision yazılımı ile değerlendirilerek nokta koordinatlarına dönüştürülmektedir. Yedi nokta üzerinden kalibrasyon sağlanmaktadır.

Coğrafi bilgi sistemleri (CBS) karmaşık planlama ve yönetim sorunlarının çözülebilmesi için tasarlanan; mekândaki konumu belirlenmiş verilerin depolanması, yönetimi, işlenmesi, analiz edilmesi ve görüntülenebilmesi işlemlerini kapsayan donanım, yazılım ve yöntemler sistemidir (Maguire, 1991, 9) CBS bugün sosyal bilimler de dâhil olmak üzere çok farklı alanlarda kullanılmaktadır (Eyyüboğlu ve Aktaş, 2016, 103-116). Bu araştırmada mekânsal veriler (coğrafi bilgi sistemi platformlarında üretilen haritalar üzerinden elde edilen veriler) kullanılmaktadır. Verilerin değerlendirilmesinde mekânsal nokta örüntüleri dikkate alınmaktadır. Bir mekânsal nokta örüntüsü, bir araştırma bölgesindeki nokta konumlarının kümesidir. Buradaki mekânsal nokta örüntü işlemlerinde veri setinin, araştırma bölgesindeki ilgili tüm olayların ölçülmüş olduğu bir "haritalandırılmış nokta örüntü” sunduğu varsayılmaktadır.

$\mathrm{Bu}$ çalışmada iki farklı tasarım biçimi kullanılsa da tasarım biçimi farklılıklarına ilişkin sonuçlara ve katılımcıların demografik farklılıkları ile ilgili sonuçlara bu çalışmada yer verilmemiş̧tir. (Tasarımlarla ilgili bulgu ve sonuçlar için bkz. Onursoy, 2017, 20-29)

Şekil 1. Hazırlanan Maket Sayfalar

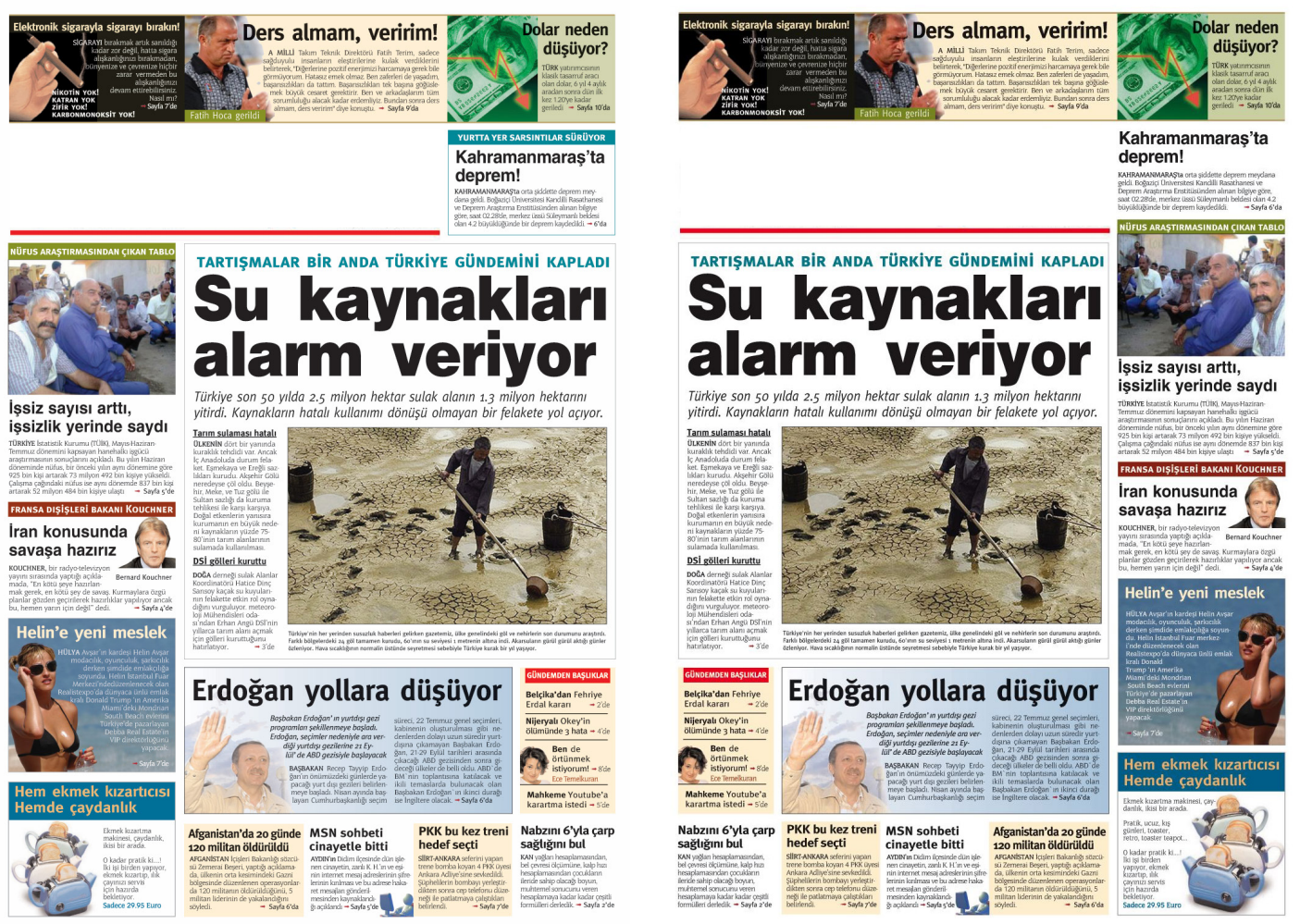

Hazırlanan maket sayfaların küçültülmüş renkli versiyonları örnek olarak şekilde gösterilmektedir. Araştırmada aynı sayfaların siyah beyaz versiyonları da kullanılmaktadır. 


\section{Bulgular}

Araştırmaya haftada dört gün gazete okuyan 147 kadın ve 173 erkek olmak üzere toplam 320 öğrenci katılmaktadır. Her bir katılımcı göz takip sistemi kullanılarak önlerine konulan tek sayfalık gazete örneğini okumaktadır. Hazırlanan maket sayfalar üzerinde göz takibi yapılmaktadır. Deneysel çalışma öncesinde katılımcıların demografik bilgilerini ve medya alışkanlıklarını sormak için kısa bir sormaca hazırlanmıştır. Haber kutularında ve fotoğraflarda renkli ve siyah-beyaz kullanım tercihleri sorgulanmıştır. Sormacanın yanıtlanmasının ardından gözlük biçimindeki göz takibi cihazı katılımcının izniyle başına takılmış gerekli kalibrasyon ayarlamalarının ardından önüne konulan gazete maketi sayfasını okuması sağlanmıştır. Katılımcıların büyük çoğunluğu üniversite lisans eğitim düzeyine sahiptir.

Sormacada gazetelerde kullanılmasını tercih ettikleri renkler sorulduğunda yaklaşı $\% 39$ 'u mavi tonlu renkleri, \%16'sı yeşil tonları, \%17'si siyah ve gri tonları, \%12'si kırmızı tonları, \%8'i sarı ve turuncu tonları tercih ederken, \%9'u kararsız olduğunu belirtmektedir (Şekil 2).

Şekil 2. Katılımcıların Gazetelerde Kullanılmasını İstedikleri Renk Siklığı

\begin{tabular}{|l|l|l|}
\hline Renkler & Sıklık & Yüzde \\
\hline Lacivert /mavi tonları & 124 & 38,8 \\
\hline Gri/siyah tonları & 54 & 16,9 \\
\hline Yeşil tonları & 52 & 16,3 \\
\hline Kırmızı/pembe tonları & 38 & 11,9 \\
\hline Kararsız & 27 & 8,4 \\
\hline Sarı/Turuncu tonları & 25 & 7,8 \\
\hline Toplam & 320 & 100,0 \\
\hline
\end{tabular}

Sormacada katılımcıların okumak istediği gazetelerin renkli mi yoksa siyah-beyaz tercihleri sorulduğunda, büyük çoğunluk (\%69) renkli gazete görmek istediğini belirtmektedir (Şekil 3).

Şekil 3. Katılımcıların Renk Tercihleri

\begin{tabular}{|l|l|l|}
\hline \multicolumn{2}{|l|}{ Sizin gazeteniz renkli mi yoksa siyah-beyaz mı olmalıdır? } \\
\hline & Sıklık & Yüzde \\
\hline Renkli olmalı & 220 & 68,8 \\
\hline Fark etmez & 84 & 26,2 \\
\hline Siyah-beyaz olmalı & 16 & 5,0 \\
\hline Toplam & 320 & 100,0 \\
\hline
\end{tabular}

Katılımcıların ortalama $\% 68$ 'i haber fotoğraflarının renkli olmasını, \%5'i siyahbeyaz olmasını belirmekte, \%27'si de renkli ya da siyah beyaz olmasının fark etmeyeceğini belirtmektedir (Şekil 4).

Şekil 4. Katıllmcıların Fotoğrafta Renk Tercihleri

\begin{tabular}{|l|l|l|}
\hline Haber fotoğrafları renkli mi yoksa siyah-beyaz mı olmalıdır? \\
\hline Gazete & Sıklık & Yüzde \\
\hline Renkli olmalı & 217 & 67,8 \\
\hline Fark etmez & 88 & 27,5 \\
\hline Siyah-beyaz olmalı & 15 & 4,7 \\
\hline Toplam & 320 & 100,0 \\
\hline
\end{tabular}


Şekil 5. Sayfaya Girişi ilk olarak hangi eleman sağlar?

\begin{tabular}{|c|c|c|c|c|c|c|}
\hline \multirow{2}{*}{ Sayfa elemanları } & \multicolumn{4}{|c|}{ Cinsiyet } & \multirow{2}{*}{ Toplam } & \multirow[b]{2}{*}{$\%$} \\
\hline & Kadın sayısı & $\%$ & Erkek sayısı & $\%$ & & \\
\hline $\begin{array}{l}\text { Başlığı en büyük olan } \\
\text { haber }\end{array}$ & 96 & $\% 30$ & 100 & $\% 31,3$ & 196 & $\% 61,3$ \\
\hline $\begin{array}{l}\text { Fotoğrafı en büyük olan } \\
\text { haber }\end{array}$ & 15 & $\% 4,7$ & 9 & $\% 2,8$ & 24 & $\% 7,5$ \\
\hline $\begin{array}{l}\text { Logonun üstünde yer alan } \\
\text { haber }\end{array}$ & 17 & $\% 5,3$ & 19 & $\% 5,9$ & 36 & $\% 11,3$ \\
\hline $\begin{array}{l}\text { Çarpıcı rengin içine } \\
\text { yerleştirilen haber }\end{array}$ & 3 & $\% 0,9$ & 4 & $\% 1,3$ & 7 & $\% 2,2$ \\
\hline Diğer & 16 & $\% 5,0$ & 41 & $\% 12,8$ & 57 & $\% 12,8$ \\
\hline Toplam & 147 & $\% 45,9$ & 173 & $\% 54,1$ & 320 & $\% 100$ \\
\hline
\end{tabular}

Katılımc1ların büyük çoğunluğu renkli gazete tercih etmesine rağmen "İlk olarak sayfaya girişi nereden yaparsınız?” sorusuna büyük çoğunluk başlığı en büyük olan haberden $(\% 61,3)$ karşıllğını vermektedir. Renkli hatta çarpıcı renk içine yerleştirilen haberden sayfaya giriş yaptığını belirtenlerin oranı ilginç şekilde \%2'dir. Katılımcılar haber okumada renkli sayfalar tercih ettiklerini belirtmelerine rağmen okumaya giriş için rengin etkili olmadığı ortaya çıkmaktadır (Şekil 5).

Göz takibi kayıtlarından elde edilen sonuçlara göre renkli sayfalarda göz hareketlerinde yatay bir yayılım görülürken, siyah beyaz sayfalardaki göz hareketlerinde dikey bir dağılım gözlenmektedir. Yani katılımcılar renkli kısımlarda sayfaların üst kısımlarına takılıp kalırken, siyah beyaz sayfalarda dikey şekilde yukarıdan aşağıya doğru kayan bir göz hareketi gerçekleştirmektedir (Şekil 6).

Şekil 6. Katılımcıların Sayfaya Göz Hareketi Yön

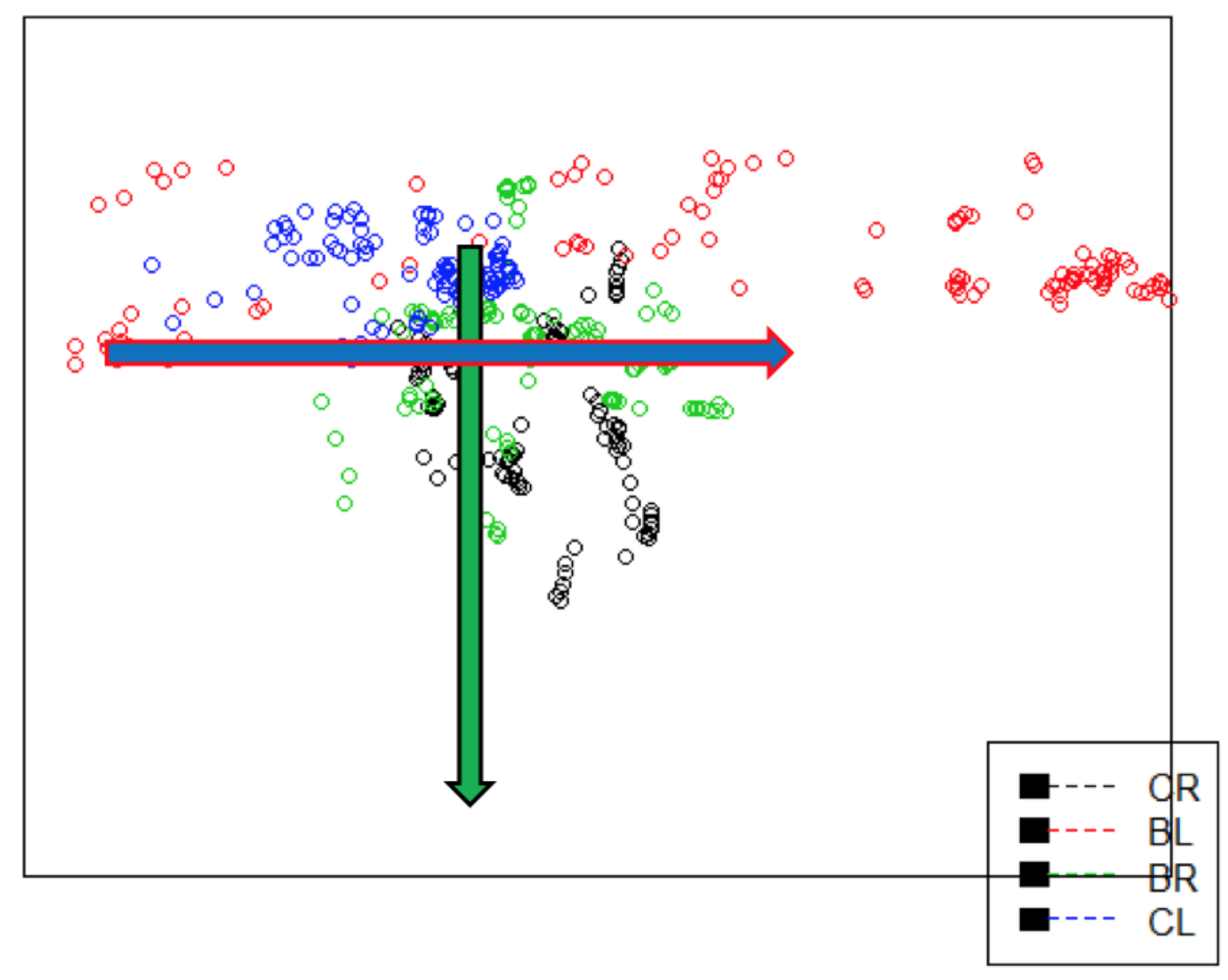


Katılımcıların sayfaya girişin ilk beş saniyesinde renkli ve siyah beyaz maket sayfalardaki göz hareketi yönelimleri.

Siyah ve yeşil noktalar renkli her iki maket sayfalardaki göz hareketlerini (saccade), yeşil ve siyah noktalar da siyah beyaz sayfalardaki göz hareketlerini göstermektedir. Renkli sayfalarda göz hareketlerinde yatay bir yayılım görülürken siyah beyaz sayfalardaki göz hareketlerinde dikey bir dağılım gözlenmektedir (Şekil 6). Bu durum katılımcıların, renkli sayfalarda rengin etkisiyle bazı haberlere takıldığının ip uçlarını vermektedir. Siyah beyaz sayfalarda ise katılımcıların göz hareketleri aşağıya doğru inmekte, sayfa yukarıdan aşağıya doğru yönelmeyle taranmaktadır.

Şekil 7. Sol Sütunlu Renkli ve Siyah-Beyaz Maket Sayfalarda Göz Hareketleri
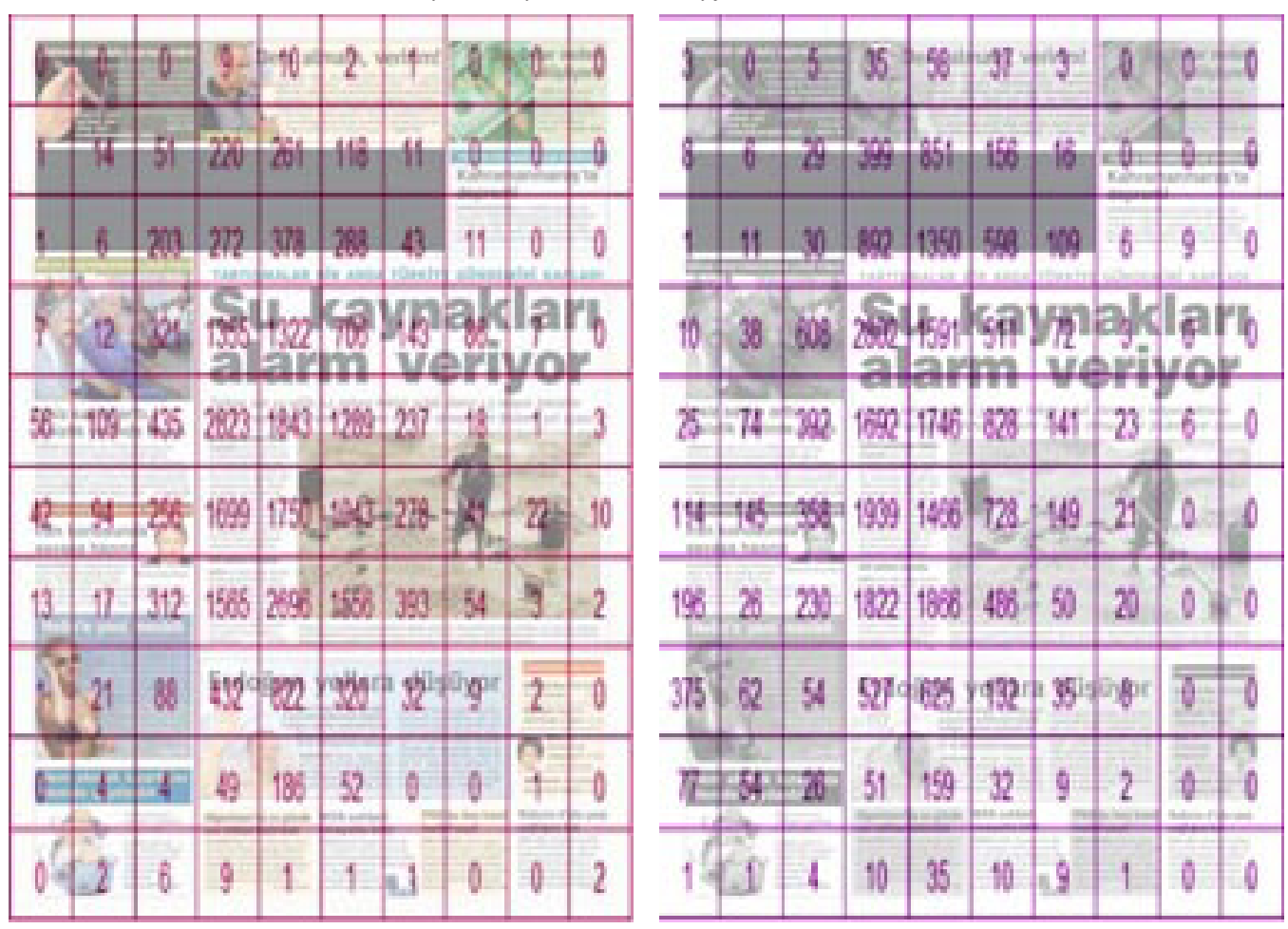

Sol sütunlu renkli ve siyah-beyaz maket sayfalarda göz hareketlerinin (Saccade) nokta örüntülerinin 10'lu bölümlemeyle karşıllaştırılması.

Göz takibi ile katılımcıların sol sütunlu iki maket sayfada genel olarak büyük başlıklı haber üzerinde göz hareketleri yoğunlaşmaktadır (Şekil 7). Siyah-beyaz makette sol sütun üzerinde renkli versiyona göre daha fazla göz hareketi tespit edilmekte ve göz hareketleri daha yaygin durumdadır. 
Şekil 8. Sağ Sütunlu Renkli ve Siyah-Beyaz Maket Sayfalarda Göz Hareketleri
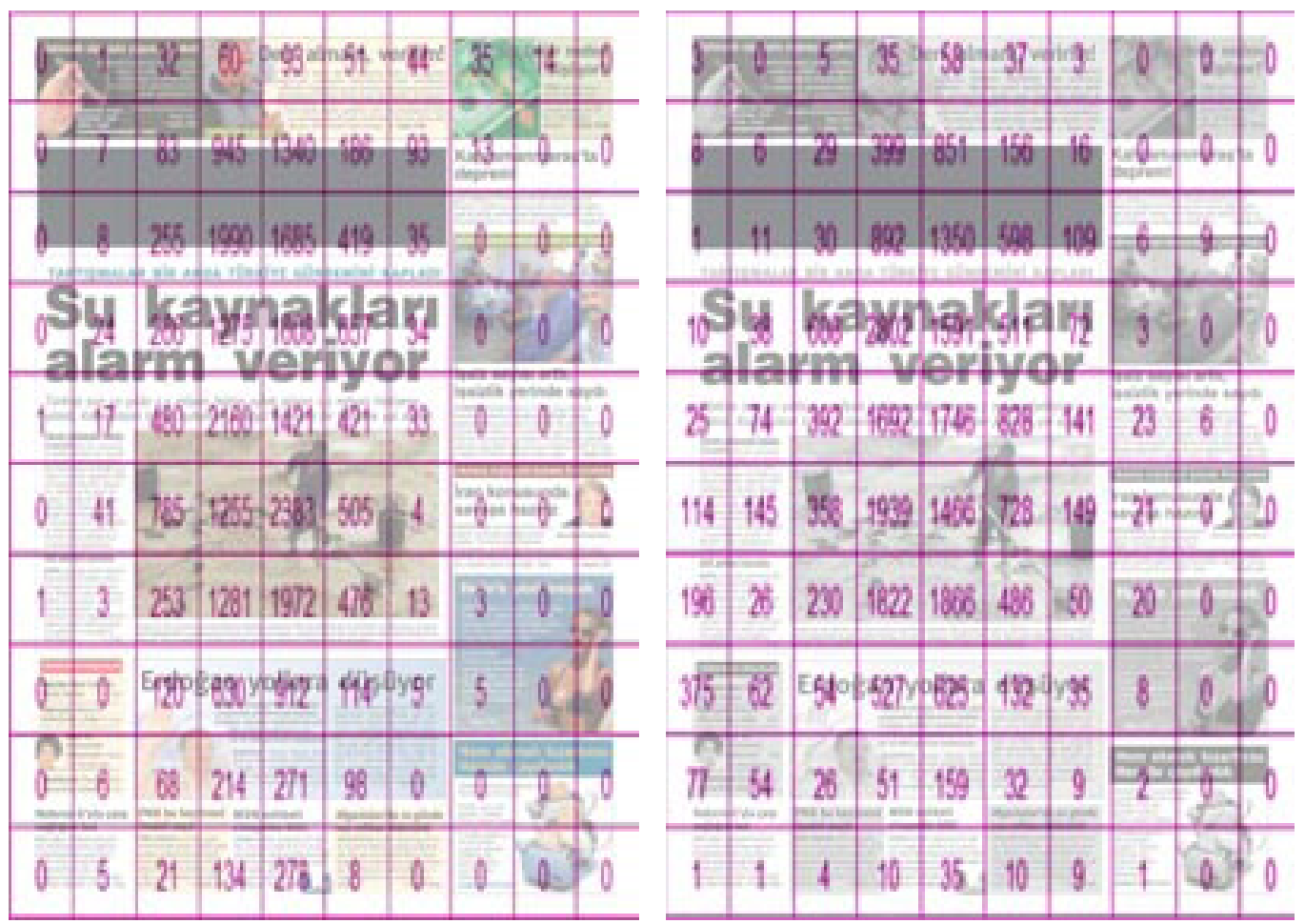

Sağ sütunlu renkli ve siyah-beyaz maket sayfalarda göz hareketlerinin (Saccade) nokta örüntülerinin 10’lu bölümlemeyle karşılaştırılması.

Göz takibi ile katılımcıların sağ sütunlu iki maket sayfada genel olarak büyük başlıklı haber ve büyük haber fotoğrafi üzerinde göz hareketleri yoğunlaşmaktadır (Şekil 8). Siyahbeyaz makette sağ sütun üzerinde renkli versiyona göre daha fazla göz hareketi tespit edilmekte ve göz hareketleri daha yaygın durumdadır. Manşet haberin yazıları üzerinde daha yoğun göz hareketinin tespit edilmesi haberin okunduğunun ifadesidir. Siyah beyaz versiyon üzerinde göz hareketleri daha yaygindır.

Bulgulara göre renk bazı alanlara dikkati çekmekte ve bazen fotoğraf bazen de yazı gibi belli alanlara takılıp kalmada etkili ancak sayfanın tamamında okunurluğu artırmaktan uzaktır. Dolayısıyla renk unsurunun dikkatli kullanılmadığı sayfa tasarımlarında haber hiyerarşisinin üzerinde olumsuz yönde etkili olması muhtemeldir. Bazı haberlerin okunurluğunu artırırken bazı haberlerin okunurluğunu azaltabilir. Haber tasarımcıları açısından bu bulgu haber hiyerarşisi oluşturma ve haberin okunabilirliğini artırmada büyük rol oynamaktadır. Diğer taraftan fotoğrafin siyah-beyaz ya da renkli olması, boyutun büyüklüğü karşısında önemini kaybetmektedir. Bulgulara göre sayfadaki en büyük fotoğraf renkli ya da siyah-beyaz her biçimde göz hareketlerini yoğun olarak toplamaktadır.

Renkli versiyonda, renkli kutu içerisinde verilen yazı ve fotoğraflar üzerinde siyahbeyaz olan haber kutularına göre daha fazla göz hareketi tespit edilmektedir. Haberin renkli zemin üzerinde yer alması göz hareketlerini yoğunlaştırarak (okunurluk ya da ilgi çekme) olumlu rol üstlenmektedir.

\section{Sonuç ve Tartışma}

$\mathrm{Bu}$ araştırmada deneysel olarak göz izleme deneyimiyle elde edilen göz hareketleri ile sormaca sonuçları karşılaştırılarak okurların haber sayfalarında rengin, siyah-beyaz karşısındaki davranışsal etkisi değerlendirilmektedir. Gazete ve haber tasarımında rengin karakteristik önemi ve etkisine odaklı bu ampirik çalışmada izleyicilerin yaptıkları davranışlar ve düşündükleri tam olarak birbiriyle örtüşmemektedir. 
Haber tasarımlarında büyük oranda renkli gazete olmasını ve çoğunlukla mavi tonların kullanılmasını tercih ettiğini ifade eden katılımcılar, göz hareketlerine göre genel olarak başlık ve fotoğraf büyüklügünden daha çok etkilenmektedir.

Sayfaya ilk giriş ya da okumaya başlamada renkli sayfalarda göz hareketleri yatay bir yayılma gösterirken siyah beyaz sayfalarda dikey bir yayılma göstermektedir. Renk okuru etkilemekte bazı haberlerde; fotoğraf ya da metin üzerinde sabitlenme davranışı göstermelerine neden olmaktadır. Renk belli alanlara odaklanmayı sağlarken, siyah-beyaz sayfaların neredeyse tamamı okur tarafından görülmektedir. Her iki versiyonda da okunurlukta haber büyüklüğü, başlık büyüklüğü ve fotoğraf büyüklüğü etkili olmakta ve renk unsurunun etkisini gölgede bırakmaktadır. Renkli haber kutusu okuma ya da ilgiyi odaklamaktadır. Bazı haberlerin okunurluğunu artırırken bazı haberlerin okunurluğunu azaltabileceği için renk unsuru sayfa tasarımlarında dikkatli kullanılmalıdır. Fotoğraflarda renk kullanımı, boyut büyüklüğü karşısında önemini kaybetmektedir.

Sonuç olarak renk kullanılırken, ilgi çekmek ve okunurluğu artırmak arasındaki dengeyi iyi ayarlamak gerekmektedir. Katılımcılar renkli sayfalar isteseler de uygulamada rengin okumayı artırmadığı ortaya çıkmaktadır. Renk ayırt etmeyi sağlar ve algı sürecini hızlandırır. 


\section{Kaynakça}

Andersen, S. K., Müller, M. M. and Hillyard, S. A. (2009). "Color-selective attention need not be mediated by spatial attention". Journal of Vision, 9 (2). doi:10.1167/9.6.2, http:// jov.arvojournals.org/article.aspx? articleid=2204014.

Arıkan, A. (2008). Grafik Tasarımda Görsel Algı. Konya: Eğitim Akademi Yayınları.

Bellizzi, J. A., Crowley, A. E. and Hasty, R.W. (1983), "The Effects of Color in Store Design," Journal of Retailing, 59 (1), 21-43.

Birren, F. (1978). Color and Human Response, New York: Van Nostrand Reinhold.

Bousfield W. A., Esterson J., \& Whitmarsh G. A. (1957). The effects of concomitant colored and uncolored pictorial representations on the learning of stimulus words. Journal of applied psychology, 41, 165-168.

Brawn, P. Snowden, R. J. (1999). "Can one pay attention to a particular color?" Perception \& Psychophysics, 61, 860-873.

Coulter, R., Coulter, M. and Glover, J. (1984). "Details and Picture Recall, Bulletin of the Psychonomic Society, 22 (4), 327-329.

Deregowski, J. (1976). 'On Seeing a Picture for the first time. Leonardo, 9, 19-23.

Detenber, B. H. \& Winch, S. P. (2001) The impact of color on emotional responses to newspaper photographs, Visual Communication Quarterly, 8 (3), 4-14, DOI: $10.1080 / 15551390109363461$ To link to this article: http://dx.doi. org/10.1080/15551390109363461, Published online: 06 Jun 2009. Erişim tarihi: 19.04.2017

Eyesenck M.W. and Keane M.T. (2000) Cognitive Psychology. A Student's Handbook, 4th Edition. London: Psychology Press.

Eyyüboğlu, B. B. ve S. G. Aktaş, (2016). Sosyal Bilimler ve Coğrafi Bilgi Sistemleri Uygulamaları Kesişiminde Mekân Kavramı, SDÜ Fen Edebiyat Fakültesi Sosyal Bilimler Dergisi, 39, 103-116.

Franken, R. E. (1977). "Picture -Recognition memory as a function of picture organization and age", Perceptual and motor skills, 44, 1151-1154.

Garcia, M.R. and Stark, P. (1991), Eyes on the News, St Petersburg, FL: The Poynter Institute for Media Studies.

Gilbert K. (1986). 'An Ethnographic Study of news Photographers and their Working Environment,' Unpublished manuscript.

Gilbert, K. and Schleuder, J. (1990). Effects of Color and Complexity in Still Photographs on Mental Effort and Memory, Journalism Quarterly, 67 (4).

Glass, A. and Holyoak, K. (1986). Cognition, NY: Random House.

Guilford, J. P. (1934). "The Affective Value of Color as a Function of Hue, Tint, and Chroma," Journal of Experimental Psychology (June), 342-370.

Jacobs, K. W., and James F. S. (1975). "Effects of Four Psychological Primary Colors on Anxiety State," Perceptual and Motor Skills, 41 (1), 207-210.

Maguire, D. J. (1991). “An Overview and Definition of GIS”, Geographical Information 
Systems: Principles and Applications, Vol. I, NY: John Wiley and Sons.

Moore, C. M. Egeth, H. (1998). How does feature-based attention affect visual processing? Journal of Experimental Psychology: Human Perception and Performance, 24, 1296-1310.

Moore, R. S., Stammerjohan, C. A. \& Coulter, R. A. (2005). Banner advertiser-web site context congruity and color effects on attention and attitudes, Journal of Advertising, 347 (2), 71-84, DOI: 10.1080/00913367.2005.10639189.

Onursoy, S. (2017). Gazete tasarımında görsel çekim: Bir göz takibi çalışması, eKurgu: Anadolu Üniversitesi İletişim bilimleri Fakültesi Hakemli dergisi, 25 (3), 20-29.

Posner M.I., Petersen S.E. and Fox P.T. (1988) Localization of cognitive operations in the human brain. Science; 240, 1627-1631.

Poynter eye-track araştırma raporları (2004). http://www.poynterextra.org/eyetrack2004/history. htm

Schindler, P. S. (1986), "Color and Contrast in Magazine Advertising," Psychology and Marketing, 3 (2), 69-78.

Shih, S. I. \& Sperling, G. (1996). Is there feature-based attentional selection in visual search? Journal of Experimental Psychology: Human Perception and Performance, 22, 758-779.

Soysal, A. Ş., Yalçın ve K. Can, H. (2008). Bilişsel Psikoloji Kapsamında Yer Alan Dikkat Teorileri, New Symposium Journal, 46 (1). http://yenisymposium.com/Pdf/ENYeniSempozyum-7230cb0c.pdf

Thomas, J. M., Hewett, K. and Roth, M. S. (2000). "Managing Images in Different Cultures: A Cross-National Study of Color Meanings and Preferences," Journal of International Marketing, 8 (4), 90-107.

Treisman, A. (1977). Focused Attention in the Perception and Retrieval of Multidimensional Stimuli, Perception and Psychophysics, 22, 1-11.

Treisman A. and Gelade, G. (1980). "A Feature-integration Theory of Attention", Cognition Psychology, 12, 97-136.

Treisman, A., Sykes, M. and Gelade, G. (1977). "Selective Attention and Stimulus Integration", in Stanislav Dornic (Ed), Attention and performance VI, (Hillsdale, NJ: Erlbaum, 333361.

Tsal, Y. Lavie, N. (1993). Location dominance in attending to color and shape. Journal of Experimental Psychology: Human Perception and Performance, 19, 131-139.

Vierck, E. Miller, J. (2005). Direct selection by color for visual encoding. Perception \& Psychophysics, 67, 483-494.

Vierck, E. Miller, J. (2008). Electrophysiological correlates of direct selection by color. Psychophysiology, 45, 621-631.

Wicker F., (1970) Photographs, Drawings and Nouns as stimuli in Paired-associate Learning, Psychonomic Science. 18, 205-206. 